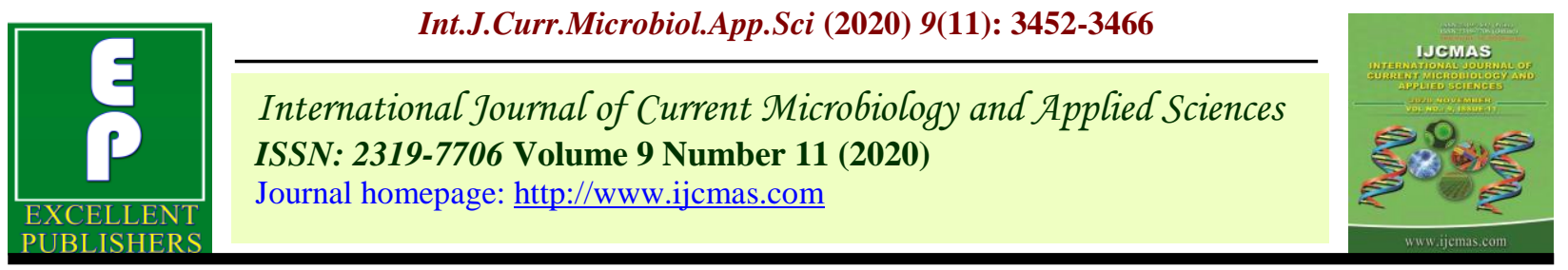

Original Research Article

https://doi.org/10.20546/ijcmas.2020.911.412

\title{
Heritable Variability and Multivariate Analysis for Physio-Morpho-Metric Traits in Tomato (Solanum lycopersicum L.)
}

\author{
Bijendra Singh, Tribhuvan Chaubey*, Sudhakar Pandey, \\ Ramesh Kumar Singh and Dhananjay Kumar Upadhyay
}

ICAR-Indian Institute of Vegetable Research (IIVR), Post Box No. 01, P. O. Jakhani

(Shahanshahpur), Varanasi, U.P., India

*Corresponding author

\section{A B S T R A C T}

Keywords

Tomato, ToLCV

(tomato leaf curl virus), EB (early blight), Heritability, principal component analysis (PCA), Multivariate analysis (MVA)

Article Info

Accepted:

24 October 2020

Available Online:

10 November 2020
Eighty two extant cultivars of tomato (Solanum lycopesicum L.) were evaluated in field and glasshouse condition for analyzing the multivariate analysis of twenty diverse physiomorpho-metric traits including tomato leaf curl virus (ToLCV) and early blight (EB) disease. Three genotypes Punjab Varkha Bahar-1, Punjab Varkha Bahar-2 and Swarna Naveen showed moderate resistant reaction for ToLCV and Kashi Sharad was highly resistant for EB disease. Whereas, highest value of GCV, PCV and GA\% were found for fruit thickness of pericarp but highest heritability and genetic advancement was recorded for the average weight which indicated additive gene action. Most of morphological characters showed maximum value in PCA II group but highest total variance percent $(61.03 \%)$ accounted in PCA I and lowest $(4.71 \%)$ in PCA IV group. There were fourteen clusters distinguished in the cluster analysis. In Mahalanobis $\mathrm{D}^{2}$ distance analysis, maximum genotypes grouped in cluster ' 1 ' and ' 3 ', whereas, remaining clusters had single diverse genotype. However, the inter cluster distance was found maximum to the tune of 52.95 between cluster ' 13 ' and ' 11 ' and minimum (7.11) between cluster ' 4 ' and ' 6 '. The findings indicated that breeding between the genotypes from clusters ' 11 ', ' 13 ' and ' 4 ' can be utilized for getting superior recombinants.

\section{Introduction}

Tomato (Solanum lycopersicum L.) is grown globally but it has a great variability on the level of genetics and genomics (Foolad, 2007). The lead role of tomato morphology has been decided to enhance the yield, disease resistance, earliness and improvement of fruit quality characteristics (Foolad, 2007; Singh et al., 2014; 2015). Limited cultivars of tomato are available for resistance to fungal and viral diseases because of less stability at the phenotypic level (Kissoudis et al., 2014). Today, tomato leaf curl virus (ToLCV) and early blight (EB) both are the most serious problem for this crop in tropical and subtropical regions around the world (Singh et al., 2010; 2012; 2019; Ramesh and Praveen, 2019). Earlier, upto $100 \%$ yield losses by ToLCV and upto $75 \%$ by early blight has 
been reported in many studies (Singh et al., 2012; 2015; 2019). For surviving or increasing the yield capacity of tomato the development of resistant varieties is the need of the hour. In the present scenario, highest resistance against the ToLCV and EB diseases have been reported in wild species and is limited in commercial tomato cultivars (Chaerani and Voorrips, 2006; Singh et al., 2014; 2015; 2017; 2019).

In India, high genetic variability conserved and maintained at National Bureau of Plant Genetic Resources (NBPGR), New Delhi and ICAR-Indian Institute of Vegetable Research (IIVR), Varanasi. The evaluation of germplasm, identification of variability is essential for maintaining and utilizing the genetic resources for present and future genetic improvement of the crop (Foolad, 2007). It has been claimed that from last two decades cultivated tomatoes characteristically have low genetic diversity, and losing of genetic heritability among the commercial tomatoes (Gonzalo and Knaap, 2008; Reddy et al., 2013). In this regard, it is necessary to partitioning of the total variability into heritable and non-heritable components and evaluated the genetic diversity among the various traits and to know the superiority of genetic advance after selection (Mohamed et al., 2012; Spaldon and Kumar, 2017; Nankar et al., 2020).

Hence, the genetic variance of any morphometric or quantitative trait is indicated additive variance (heritable) and non-additive variance and comprise dominance and epistasis (non-allelic interaction) altered by environmental conditions (Iqbal et al., 2014; Kumar et al., 2017; Spaldon and Kumar, 2017). The present study was to identify the ToLCV and EB resistant cultivars, and to quantify the genetic variability, heritability, principal component analysis and genetic differences in tomato for physio-morphometric traits.

\section{Materials and Methods}

\section{Experimental materials, site and design management}

Eighty two extant cultivars of tomato received from diverse climatic zone of state agricultural universities (SAUs), central agriculture universities (CUs) and research institutes (RIs) of India (Figure 1). Tomato seeds were healthy and kept $>85 \%$ germination capacity, $<8 \%$ moisture content and having $>98 \%$ genetic purity. Collected seed materials were maintained in experimental research field of DUS (Distinctiveness, Uniformity and Stability) testing at ICAR-Indian Institute of Vegetable Research (IIVR), Varanasi. This institute is situated approximately $20 \mathrm{~km}$ away from Varanasi district in direction of south-west near to the bank of Ganga River and exists between $83.00^{\prime} \mathrm{E}$ longitude and $25.19^{\prime} \mathrm{N}$ latitude at an elevation of 128.93 masl. This research farm falls under semi-arid region with an annual mean rainfall approximately $1113.3 \mathrm{~mm}$ with average number of 47 rainy days. The highest temperature goes on up to $46^{\circ} \mathrm{C} \pm 1$. During experimentation ninety tomato plants were transplanted in three replications of randomized block design. Each replication was made by 30 plants at the spacing of $45 \mathrm{~cm}$ (plant to plant) x $60 \mathrm{~cm}$ (row to row). All the agronomical and cultural practices followed to raise the crop.

\section{Data observation}

Twenty characters observed from 82 extant cultivars of tomato under field and glasshouse conditions. Data started from the stage of appearance of first flower flush to maturity of fruits according to descriptor of DUS guidelines published by protection of plant varieties and farmers rights authority (PPV\&FRA, 2009). Among the characters 18 morphological traits including yield were 
recorded from stem (length of internodes between 1st and 4th inflorescence in $\mathrm{cm}$ ), leaves (leaf length in $\mathrm{cm}$, leaflet length in $\mathrm{cm}$, leaf width in $\mathrm{cm}$, leaflet width in $\mathrm{cm}$ ), flowers (calyx size in $\mathrm{cm}$, joint peduncle length from abscission layer to calyx in $\mathrm{cm}$, time of flowering (50\% of the plants with at least one open flower from seed sowing in days) and fruits (average weight of 10 fruits in gram, number of fruit/plant, fruit length in $\mathrm{cm}$, fruit width in $\mathrm{cm}$, size of scar around peduncle diameter in $\mathrm{cm}$, size of core in cross section in relation to total diameter in $\mathrm{mm}$, thickness of the pericarp in $\mathrm{cm}$, number of locules, time of maturity from seed sowing and yield/plant in $\mathrm{kg}$.

The yield/plant (kg) was calculated by multiplying the number of fruits/plant from average fruit weight $(\mathrm{g})$ and divided by 1000 . Besides morphological traits, tomato leaf curl virus (ToLCV) and early blight (EB) disease scores were also recorded.

\section{Disease scoring and evaluations}

\section{Tomato leaf curl virus (ToLCV)}

For screening against tomato leaf curl virus disease, plants were examined on 30, 60 and 90 days after transplanting (DATP) in field conditions and 15, 30, 45 and 60 days after transplanting (DATP) in glasshouse condition (Singh et al., 2015; 2019). The symptom severity for ToLCV was recorded on six point (0-5) scale (Singh et al., 2015). The coefficient of infection $(\mathrm{CI})$, percent disease incidence (PDI) and response value (RV) were calculated as per given formula of Singh et al., (2015).

\section{Early blight (EB)}

For screening against early blight disease, plants were examined after symptom expression at 45, 60, 75 and 90 days after transplanting (DATP) in field conditions and 7, 14, 21 and 28 days after transplanting (DATP) in glasshouse condition (Pandey et al., 2003; Singh et al., 2012).

The early blight symptoms were recorded on a scale of 0-5 as used by Pandey et al., (2003) and Singh et al., (2012). The percent disease incidence (PDI) was calculated by using formula of Pandey et al., (2003).

\section{Statistical analysis}

All the statistical analysis viz, genetic variability, heritability, genetic advances, principal component analysis (PCA) and cluster distances ( $\mathrm{D}^{2}$ analysis), were done by a statistic software INDOSTAT version 8.5 (www.indistat.com) using 20 morpho-metric traits of 82 tomato extant cultivars.

\section{Genetic variability, heritability and genetic advance analysis}

Environmental, genotypical and phenotypical variances, environmental coefficient variation (ECV), genotypic coefficient of variation (GCV), phenotypic coefficient of variation (PCV), heritability in broad sense (h2b), genetic advance in percentage of mean (GA and GA\%) were calculated on the basis of formula given by Burton and De Vane (1953); Johnson et al., (1955); Hanson et al., (1956); Singh and Choudhary (1985), respectively.

\section{Principal component analysis (PCA)}

The principal component analysis was used to determine the variability in 20 morpho-metric characteristics of 82 tomato extant cultivars. Similarly multivariate analysis, PCA was performed the transformation of the initial variables into a limited number of uncorrelated new variables by the following guidelines of Rao (1952); Hair et al., (2009). 


\section{Cluster distances $\left(\mathrm{D}^{2}\right.$ analysis $)$}

To determine the cluster distances a dendrogram was constructed with standardized 20 morpho-metric traits of all 82 extant cultivars of tomato. The data of all the extant cultivars were subjected to multivariate analysis utilizing Mahalanobis $\mathrm{D}^{2}$ statistic as suggested by Mahalanobis (1936). Tomato cultivars were grouped into various clusters based on Tocher's method as suggested by Rao (1952).

\section{Results and Discussion}

\section{Selection of tomato cultivars for ToLCV and $E B$ resistance}

Eighty two extant cultivars of tomato were screened against tomato leaf curl virus (ToLCV) and early blight (EB) disease resistance under field and glasshouse conditions (Table 1). Thus, tested cultivars for ToLCV were categorized into highly resistant (0), resistant (0), moderately resistant (3), moderately susceptible (9), susceptible (41) and highly susceptible (29). In this result we found that all the extant cultivars were infected by ToLCV at level of moderately susceptible to highly susceptible but three cultivars ('Punjab Varkha Bahar-1', 'Punjab Varkha Bahar-2' and 'Swarna Naveen') were moderately resistant. However, none genotype was observed with highly resistant or resistant reaction. Whereas, in result of screening for early blight (EB) disease these tested 82 extant cultivars were categorized into highly resistant (1), resistant (0), moderately resistant (14), moderately susceptible (43), susceptible (20) and highly susceptible (4). In current finding all cultivars were showed their disease incidence from moderately susceptible to highly susceptible. Only 'Kashi Sharad' was highly resistant against EB disease (Table 1).
Environmental, genotypic and phenotypic variances and coefficient of variation

The analysis of variance showed that there were highly significant $(\mathrm{P}<0.01)$ differences among the genotypes for all the characters (Table 2). This may be attributed to the existence of large variability among the cultivars under the study.

The estimates of minimum and maximum range with general mean, environmental, genotypical and phenotypical variances along with the environmental (ECV), genotypic (GCV), phenotypic coefficient of variation (PCV), broad sense heritability, genetic advance and genetic advance as percent of the mean for twenty characters in eighty two extant cultivars of tomato are presented in Table 3. The results revealed that a considerable variation was recorded in most of the characters. Among the characters maximum range of mean values were observed for average fruit weight (25.000$120.000 \mathrm{~g}$ ) and minimum range was recorded with flower calyx size $(0.333-1.600 \mathrm{~cm})$. While, the general mean value of characters was observed highest and lowest for time of maturity (119.911 days) and thickness of pericarp $(0.508 \mathrm{~cm})$, respectively.

The results revealed that the considerable environmental, phenotypical and genotypical variances among the genotypes for the most of traits found under consideration (Table 3). Among the traits flower calyx size $(0.007 \mathrm{~cm})$ showed lowest environmental variance but time of maturity (12.050days) and PDI for ToLCV (10.692\%) were exhibited highest environmental variances. Whereas, genotypical and phenotypical variances reported lowest value for fruit cluster size $(0.053$ and $0.055 \mathrm{~cm})$ and highest value for average fruit weight $(555.824 \mathrm{~g}$ and $556.545 \mathrm{~g}$ ). 
For all characters under the study the values of phenotypic coefficient of variation (PCV) were greater than genotypic coefficient of variation $(\mathrm{GCV})$. While, the values of all characters of environmental coefficient of variation $(\mathrm{ECV})$ were lesser than $\mathrm{GCV}$ and PCV (Table 3). It was also observed that the most of the characters showed less difference between GCV and PCV values.

The lowest and highest environmental coefficient of variation noted for average fruit weight $(2.033 \mathrm{~g})$ and thickness of pericarp $(24.164 \mathrm{~cm})$. Whereas, lowest and highest values for genotypic and phenotypic coefficient of variation were observed for time of maturity (6.607 and 6.815days) and thickness of pericarp $(54.305$ and $56.068 \mathrm{~cm})$.

Estimate of heritability in broad sense, genetic advance and genetic advance percent

In present study, the highest heritability $\left(h^{2}\right)$ and genetic advance were observed for average fruit weight $(0.999$ and $62.200 \mathrm{~g})$, PDI\% of EB (0.992 and $48.425 \%)$ and PDI\% of ToLCV (0.985 and 40.708) while, the highest genetic advance as percentage of mean were observed for thickness of pericarp (138.856), size of scar around peduncle (120.994) and PDI\% of EB (117.659) (Table 3). However, lowest value for heritability, genetic advance and genetic advance as percent of mean was exhibited by leaf width $(0.876 \%)$, flower calyx size $(0.593)$ and time of maturity (16.910), respectively (Table 3 ).

\section{Principal component analysis (PCA)}

In present study, the principal component analysis was carried out on the horticultural traits and disease parameters to describe relations among the different characteristics as well as detect important components.
Figure 2 shows the three-dimensional principal component score plot using the two score vectors, PCA I and PCA II, which account for most variation. This was also verified by the grouping of 82 extant cultivars of tomato and their traits in the direct surrounded by PCA I and PCA II (Figure 2). In results of this study, it has been found that contribution of the first four components in total variance and cumulative variance expressed in percentage along with root mean of Eigen value (Table 4). The first principal component (PCA I) accounts for approximately $61.03 \%$ of the total variance and cumulative variance.

The most important traits in the first principal component was average fruit weight, number of fruit per plant, number of locules and size of scar around fruit peduncle with highest PCA value $0.94246,-0.21828,0.14318$ and 0.10416 , respectively (Table 4). Minimum and maximum value of PCA I range was 0.00092 (leaflet width) to 0.9426 (average fruit weight). The second principal component (PCA II) accounts for approximately $11.45 \%$ of the total variance along with $72.48 \%$ of the cumulative variance (Table 4). The most important characters with high value of this component defined by number of locules (0.80972), total yield per plant (0.28064), fruit length (-0.23795), leaflet length $(-0.20185)$, thickness of the pericarp (-0.17606) and fruit width (0.17472).

The third principal component (PCA III) contributes $5.02 \%$ of the total variance and $77.50 \%$ of the cumulative variance. The most important traits found in this component were PDI\% for EB (-0.85283), fruit length ($0.28554)$, total yield per plant $(-0.26345)$ and time of 50\% flowering (-0.21407). The fourth component (PCA IV) explained $4.71 \%$ of the total variance and $82.21 \%$ of the cumulative variance (Table 4). 
Table.1 Scale of scoring and reaction of $82^{*}$ extant cultivars of tomato for tomato leaf curl virus and early blight disease as screened under field and glasshouse condition

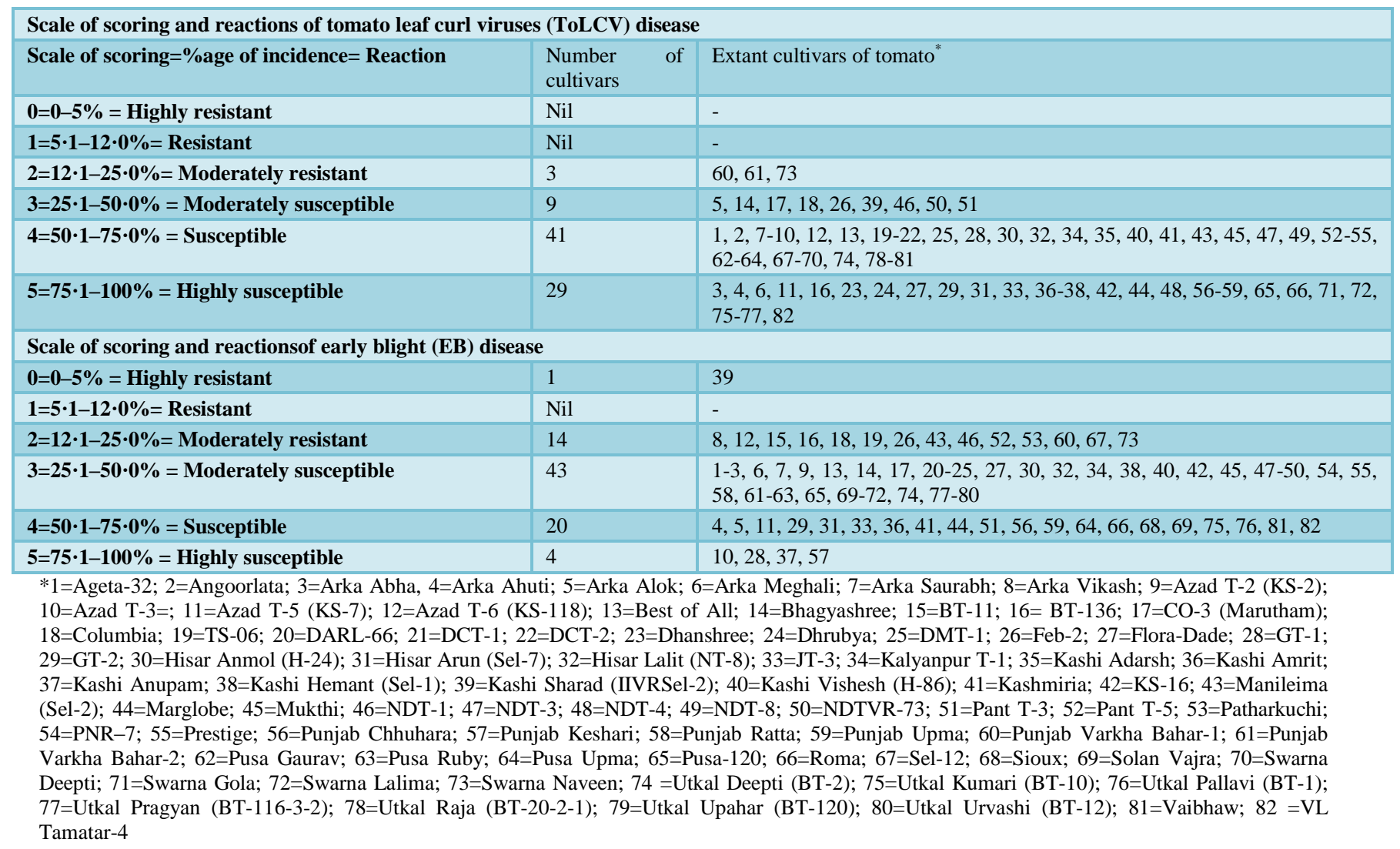

Table.2 Analysis of variance for 20 characters in 82 extant cultivars of tomato

\begin{tabular}{|c|c|c|c|c|}
\hline SN. & Characters & ${ }^{\#} \mathbf{M S}_{\mathbf{r}}\left(\mathbf{2}^{*}\right)$ & ${ }^{\#} \mathbf{M S}_{\mathrm{g}}\left(\mathbf{8 1}{ }^{*}\right)$ & ${ }^{\#} \mathrm{MS}_{\mathrm{e}}\left(162^{*}\right)$ \\
\hline 1. & Stem: Length of internode between 1 st and 4 th inflorescence $(\mathrm{cm})$ & 58.391 & $269.066^{* *}$ & 8.871 \\
\hline 2. & Leaf: Length $(\mathrm{cm})$ & 18.802 & $61.145^{* *}$ & 2.136 \\
\hline 3. & Leaflet: Length $(\mathrm{cm})$ & 0.045 & $10.658^{* *}$ & 0.245 \\
\hline 4. & Leaf: Width $(\mathrm{cm})$ & 0.308 & $43.849^{* *}$ & 5.434 \\
\hline 5. & Leaflet: Width $(\mathrm{cm})$ & 0.299 & $1.847^{* *}$ & 0.140 \\
\hline 6. & Flower: Calyx size $(\mathrm{cm})$ & 0.009 & $0.165^{* *}$ & 0.007 \\
\hline 7. & Jointed peduncle: Length (from abscission layer to calyx) $(\mathrm{cm})$ & 0.015 & $0.301^{* *}$ & 0.013 \\
\hline 8. & $\begin{array}{l}\text { Time of flowering ( } 50 \% \text { of the plants with at least one open flower from seed } \\
\text { sowing) (days) }\end{array}$ & 54.272 & $114.834^{* *}$ & 6.178 \\
\hline 9. & Fruit: Average weight of 10 fruits $(\mathrm{g})$ & 8.472 & $1669.634^{* *}$ & 2.162 \\
\hline 10. & Number of fruits/plant & 9.541 & $282.545^{* *}$ & 3.824 \\
\hline 11. & Fruit: Length $(\mathrm{cm})$ & 0.025 & $2.707^{* *}$ & 0.062 \\
\hline 12. & Fruit: Width $(\mathrm{cm})$ & 0.061 & $2.227^{* *}$ & 0.081 \\
\hline 13. & Fruit: Size of scar around peduncle (diameter) $(\mathrm{cm})$ & 0.076 & $0.530^{* *}$ & 0.012 \\
\hline 14. & Fruit: Size of core in cross section(in relation to total diameter) $(\mathrm{mm})$ & 0.002 & $0.791^{* *}$ & 0.037 \\
\hline 15. & Fruit: Thickness of the pericarp $(\mathrm{cm})$ & 0.019 & $0.244^{* *}$ & 0.015 \\
\hline 16. & Fruit: Number of locules & 0.012 & $3.446^{* *}$ & 0.037 \\
\hline 17. & Time of maturity (from seed sowing) & 108.955 & $200.346^{* *}$ & 12.049 \\
\hline 18. & PDI $(\%)$ for ToLCV & 16.234 & $734.536^{* *}$ & 10.692 \\
\hline 19. & $\mathrm{PDI}(\%)$ for $\mathrm{EB}$ & 174.634 & $1025.078^{* *}$ & 7.876 \\
\hline 20. & Yield/plant $(\mathrm{Kg})$ & 0.050 & $0.302^{* *}$ & 0.019 \\
\hline
\end{tabular}

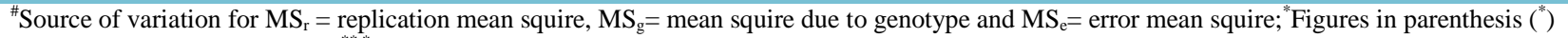
indicatedto degree of freedom, ${ }^{* *, *}$ Significant at $1 \% \& 5 \%$ probability levels, respectively 
Table.3 Estimates of range of mean and general mean, components of variance, coefficients of variations, broad sense heritability, genetic advance and genetic advance percent as per mean for 20 characters in tomato extant cultivars

\begin{tabular}{|c|c|c|c|c|c|c|c|c|c|c|c|c|c|c|}
\hline \multirow[t]{2}{*}{ Characters } & \multicolumn{2}{|c|}{ Range } & \multirow[t]{2}{*}{ GM } & \multirow[t]{2}{*}{$\mathbf{V}_{\mathrm{e}}$} & \multirow[t]{2}{*}{$\mathbf{V}_{\mathrm{g}}$} & \multirow[t]{2}{*}{$\mathbf{V}_{\mathbf{p}}$} & \multirow[t]{2}{*}{ ECV\% } & \multirow[t]{2}{*}{ GCV\% } & \multirow[t]{2}{*}{ PCV\% } & \multirow[t]{2}{*}{$\mathbf{h}^{2 \%}$} & \multirow[t]{2}{*}{ GA } & \multirow[t]{2}{*}{ GA\% } & \multirow[t]{2}{*}{ SEDM } & \multirow[t]{2}{*}{ CD\% } \\
\hline & Minimum & Maximum & & & & & & & & & & & & \\
\hline SLI (cm) & 11.400 & 60.767 & 33.641 & 8.872 & 86.732 & 89.689 & 8.854 & 27.683 & 28.151 & 0.967 & 24.178 & 71.869 & 1.710 & 4.470 \\
\hline $\mathbf{L L}(\mathbf{c m})$ & 17.267 & 37.333 & 24.461 & 2.136 & 19.670 & 20.382 & 5.975 & 18.131 & 18.456 & 0.965 & 11.502 & 47.023 & 0.840 & 2.190 \\
\hline LtL (cm) & 4.067 & 17.633 & 6.978 & 0.245 & 3.471 & 3.553 & 7.088 & 26.700 & 27.012 & 0.977 & 4.862 & 69.675 & 0.280 & 0.740 \\
\hline LW (cm) & 13.100 & 31.733 & 18.663 & 5.434 & 12.805 & 14.616 & 12.490 & 19.174 & 20.485 & 0.876 & 8.842 & 47.378 & 1.340 & 3.490 \\
\hline LtW (cm) & 2.400 & 6.300 & 4.042 & 0.140 & 0.569 & 0.616 & 9.253 & 18.668 & 19.417 & 0.924 & 1.915 & 47.381 & 0.210 & 0.560 \\
\hline FCS (cm) & 0.333 & 1.600 & 0.792 & 0.007 & 0.053 & 0.055 & 10.638 & 29.011 & 29.654 & 0.957 & 0.593 & 74.928 & 0.050 & 0.130 \\
\hline JPL (cm) & 0.433 & 2.933 & 1.243 & 0.014 & 0.096 & 0.100 & 9.337 & 24.899 & 25.475 & 0.955 & 0.799 & 64.244 & 0.070 & 0.170 \\
\hline TF & 55.333 & 88.000 & 70.907 & 6.178 & 36.219 & 38.278 & 3.505 & 8.488 & 8.725 & 0.946 & 15.455 & 21.796 & 1.430 & 3.720 \\
\hline $\mathbf{A F W}(\mathbf{g})$ & 25.000 & 120.000 & 72.346 & 2.163 & 555.824 & 556.545 & 2.033 & 32.588 & 32.609 & 0.999 & 62.200 & 85.976 & 0.844 & 2.200 \\
\hline NFPP & 11.667 & 75.000 & 24.972 & 3.825 & 92.907 & 94.182 & 7.832 & 38.599 & 38.863 & 0.987 & 25.274 & 101.210 & 1.122 & 2.925 \\
\hline FL (cm) & 3.300 & 7.233 & 4.709 & 0.062 & 0.882 & 0.903 & 5.280 & 19.941 & 20.172 & 0.977 & 2.451 & 52.039 & 0.143 & 0.372 \\
\hline FW (cm) & 3.500 & 8.067 & 5.141 & 0.081 & 0.716 & 0.743 & 5.525 & 16.457 & 16.763 & 0.964 & 2.193 & 42.652 & 0.163 & 0.425 \\
\hline FSSAP (cm) & 0.100 & 2.900 & 0.895 & 0.012 & 0.172 & 0.177 & 12.457 & 46.379 & 46.933 & 0.977 & 1.083 & 120.994 & 0.064 & 0.167 \\
\hline FSCCS $(\mathrm{mm})$ & 0.800 & 3.900 & 1.561 & 0.037 & 0.251 & 0.264 & 12.287 & 32.103 & 32.878 & 0.953 & 1.292 & 82.756 & 0.110 & 0.287 \\
\hline FTP $(\mathbf{c m})$ & 0.233 & 1.900 & 0.508 & 0.015 & 0.076 & 0.081 & 24.164 & 54.305 & 56.068 & 0.938 & 0.706 & 138.856 & 0.071 & 0.184 \\
\hline FNL & 2.000 & 6.000 & 3.402 & 0.037 & 1.137 & 1.149 & 5.645 & 31.333 & 31.502 & 0.989 & 2.799 & 82.274 & 0.110 & 0.287 \\
\hline TM & 104.333 & 139.667 & 119.911 & 12.050 & 62.765 & 66.782 & 2.895 & 6.607 & 6.815 & 0.940 & 20.277 & 16.910 & 1.992 & 5.192 \\
\hline PPTLCV (\%) & 22.233 & 91.667 & 68.489 & 10.692 & 241.281 & 244.845 & 4.774 & 22.680 & 22.847 & 0.985 & 40.708 & 59.438 & 1.876 & 4.891 \\
\hline PPEB (\%) & 12.900 & 87.733 & 41.157 & 7.876 & 339.067 & 341.693 & 6.819 & 44.740 & 44.913 & 0.992 & 48.425 & 117.659 & 1.610 & 4.198 \\
\hline TYPP (Kg) & 0.967 & 2.567 & 1.648 & 0.019 & 0.094 & 0.101 & 8.449 & 18.638 & 19.265 & 0.936 & 0.784 & 47.600 & 0.080 & 0.208 \\
\hline
\end{tabular}

$\mathrm{GM}=$ general mean; $\mathrm{V}_{\mathrm{e}}=$ environmental variance; $\mathrm{V}_{\mathrm{g}}=$ genotypical variance; $\mathrm{V}_{\mathrm{p}}=$ phenotypical variance; ECV= environmental coefficient of variation; GCV= genotypic coefficient of variation; PCV = phenotypic coefficient of variation; $\mathrm{h}^{2}=$ heritability $($ Broad Sense) $(\%)$; GA\& GA $\%=$ genetic advance at $1 \%$; SEDM= standard error difference from mean; $\mathrm{CD}=$ critical difference at 5\%; SLI= Stem: Length of internode between 1st and 4th inflorescence (cm); LL= Leaf: Length $(\mathrm{cm})$; LtL= Leaflet: Length $(\mathrm{cm})$; LW= Leaf: Width $(\mathrm{cm})$; LtW= Leaflet: Width $(\mathrm{cm})$; FCS= Flower: Calyx size $(\mathrm{cm})$; JPL= Jointed peduncle: Length (from abscission layer to calyx) $(\mathrm{cm}) ; \mathrm{TF}=$ Time of flowering (50\% of the plants with at least one open flower from seed sowing) (days); AFW= Average weight of 10 fruits $(\mathrm{g})$; NFPP = Number of fruits/plant; FL= Fruit: Length $(\mathrm{cm})$; FW=Fruit: Width $(\mathrm{cm})$; FSSAP= Fruit: Size of scar around peduncle (diameter) (cm); FSCCS = Fruit: Size of core in cross section(in relation to total diameter) $(\mathrm{mm})$; FTP= Fruit: Thickness of the pericarp $(\mathrm{cm})$; FNL= Fruit: Number of locules; $\mathrm{TM}=$ Time of maturity (from seed sowing); PPTLCV= PDI (\%) for ToLCV; PPEB= PDI (\%) for EB; TYPP= Total yield $(\mathrm{kg}) / \mathrm{plant}$ 
Table.4 Rotated components of 20 characters of tomato cultivars for principal component analysis (PCA)

\begin{tabular}{|c|c|c|c|c|c|}
\hline SN. & Characters & PCA I & PCA II & PCA III & PCA IV \\
\hline 1. & $\begin{array}{l}\text { Stem: Length of internode between } 1 \text { st and } 4 \text { th } \\
\text { inflorescence }(\mathrm{cm})\end{array}$ & 0.00562 & 0.00547 & 0.12809 & 0.24888 \\
\hline 2. & Leaf: Length $(\mathrm{cm})$ & 0.04339 & -0.16065 & -0.00206 & -0.10520 \\
\hline 3. & Leaflet: Length $(\mathrm{cm})$ & 0.05319 & -0.20185 & 0.01327 & 0.00894 \\
\hline 4. & Leaf: Width $(\mathrm{cm})$ & 0.01174 & -0.04182 & -0.00600 & -0.02197 \\
\hline 5. & Leaflet: Width $(\mathrm{cm})$ & 0.00092 & -0.04462 & -0.02300 & -0.05675 \\
\hline 6. & Flower: Calyx size $(\mathrm{cm})$ & 0.06611 & -0.03260 & 0.08030 & -0.03175 \\
\hline 7. & $\begin{array}{l}\text { Jointed peduncle: Length (from abscission layer to calyx) } \\
(\mathrm{cm})\end{array}$ & 0.06084 & 0.03532 & -0.02304 & 0.10979 \\
\hline 8. & Time of 50\% flowering (days) & 0.02476 & 0.02613 & -0.21407 & -0.07435 \\
\hline 9. & Fruit: Average weight of 10 fruits (g) & 0.94246 & -0.12409 & -0.01090 & 0.00478 \\
\hline 10. & Number of fruits/plant & -0.21828 & -0.07522 & 0.09734 & 0.39747 \\
\hline 11. & Fruit: Length $(\mathrm{cm})$ & -0.07456 & -0.23795 & -0.28554 & -0.03639 \\
\hline 12. & Fruit: Width $(\mathrm{cm})$ & -0.02653 & 0.17472 & 0.05907 & -0.01397 \\
\hline 13. & Fruit: Size of scar around peduncle (diameter) $(\mathrm{cm})$ & 0.10416 & 0.09200 & 0.03564 & 0.02331 \\
\hline 14. & $\begin{array}{l}\text { Fruit: Size of core in cross section(in relation to total } \\
\text { diameter }(\mathrm{mm})\end{array}$ & 0.00752 & 0.07876 & 0.00251 & 0.02059 \\
\hline 15. & Fruit: Thickness of the pericarp $(\mathrm{cm})$ & 0.02034 & -0.17606 & 0.02778 & 0.01262 \\
\hline 16. & Fruit: Number of locules & 0.14318 & 0.80972 & 0.17346 & 0.17584 \\
\hline 17. & Time of maturity (from seed sowing) & 0.01635 & -0.08916 & -0.06906 & -0.08311 \\
\hline 18. & PDI $(\%)$ for ToLCV & -0.08897 & 0.08368 & -0.04232 & 0.01587 \\
\hline 19. & PDI (\%) for EB & 0.03939 & 0.15316 & -0.85283 & 0.38279 \\
\hline 20. & Total yield $(\mathrm{kg}) / \mathrm{plant}$ & -0.05228 & 0.28064 & -0.26345 & -0.74791 \\
\hline \multicolumn{2}{|c|}{ Eigene Value (Root) } & 8694.86400 & 1630.83300 & 715.15580 & 670.80910 \\
\hline \multicolumn{2}{|c|}{ Total Variance \% Exp. } & 61.03269 & 11.44746 & 5.01996 & 4.70867 \\
\hline \multicolumn{2}{|c|}{ Cumulative Variance \% Exp. } & 61.03269 & 72.48017 & 77.50009 & 82.20877 \\
\hline
\end{tabular}

Table.5 Pair wise Mahalanobis distances $\left(\mathrm{D}^{2}\right)$ between fourteen intra (bold) and inter clusters (groups) of 82 extant cultivars of tomato

\begin{tabular}{|c|c|c|c|c|c|c|c|c|c|c|c|c|c|c|}
\hline$\longrightarrow$ & $\begin{array}{l}\text { SLI } \\
\text { (cm) }\end{array}$ & $\begin{array}{c}\mathbf{L L} \\
(\mathbf{c m})\end{array}$ & $\begin{array}{l}\text { LtL } \\
\text { (cm) }\end{array}$ & $\begin{array}{l}\mathbf{L W} \\
(\mathrm{cm})\end{array}$ & $\begin{array}{l}\text { LtW } \\
\text { (cm) }\end{array}$ & $\begin{array}{l}\text { FCS } \\
\text { (cm) }\end{array}$ & $\begin{array}{l}\text { JPL } \\
\text { (cm) }\end{array}$ & TF & $\begin{array}{c}\text { AFW } \\
\text { (g) }\end{array}$ & NFPP & $\begin{array}{c}\text { FL } \\
(\mathbf{c m})\end{array}$ & $\begin{array}{l}\text { FW } \\
\text { (cm) }\end{array}$ & $\begin{array}{c}\text { FSSAP } \\
(\mathbf{c m})\end{array}$ & $\begin{array}{c}\text { FSCCS } \\
(\mathbf{m m})\end{array}$ \\
\hline SLI (cm) & 11.93 & 15.41 & 23.10 & 15.25 & 17.20 & 14.84 & 14.70 & 19.63 & 17.16 & 35.51 & 20.02 & 27.90 & 27.69 & 17.38 \\
\hline $\mathbf{L L}(\mathbf{c m})$ & - & 0.00 & 31.48 & 7.11 & 21.39 & 10.93 & 12.13 & 29.08 & 13.85 & 43.24 & 11.38 & 35.37 & 19.75 & 17.44 \\
\hline LtL (cm) & - & - & 13.79 & 32.00 & 17.66 & 30.31 & 30.45 & 16.84 & 31.90 & 19.35 & 35.64 & 18.29 & 41.39 & 28.63 \\
\hline LW (cm) & - & - & - & 0.00 & 22.82 & 12.78 & 12.27 & 28.57 & 14.66 & 43.89 & 14.01 & 35.52 & 21.65 & 16.94 \\
\hline LtW (cm) & - & - & - & - & 0.00 & 24.09 & 22.43 & 22.36 & 27.88 & 24.91 & 29.45 & 20.68 & 36.55 & 23.16 \\
\hline FCS (cm) & - & - & - & - & - & 0.00 & 13.07 & 24.78 & 11.13 & 43.66 & 11.27 & 34.14 & 21.32 & 17.62 \\
\hline JPL (cm) & - & - & - & - & - & - & 0.00 & 26.59 & 16.02 & 43.42 & 17.47 & 35.73 & 25.45 & 20.55 \\
\hline TF & - & - & - & - & - & - & - & 0.00 & 26.41 & 29.09 & 30.56 & 21.56 & 35.97 & 24.31 \\
\hline AFW (g) & - & - & - & - & - & - & - & - & 0.00 & 44.73 & 11.53 & 36.88 & 15.38 & 19.10 \\
\hline NFPP & - & - & - & - & - & - & - & - & - & 0.00 & 48.59 & 20.71 & 52.95 & 40.80 \\
\hline FL (cm) & - & - & - & - & - & - & - & - & - & - & 0.00 & 39.61 & 14.16 & 19.08 \\
\hline FW (cm) & - & - & - & - & - & - & - & - & - & - & - & 0.00 & 45.21 & 32.32 \\
\hline FSSAP (cm) & - & - & - & - & - & - & - & - & - & - & - & - & 0.00 & 26.20 \\
\hline FSCCS $(\mathbf{m m})$ & - & - & - & - & - & - & - & - & - & - & - & - & - & 0.00 \\
\hline
\end{tabular}


Fig.1 Allocation of origin centres (1-22) in GIS map for 82 extant cultivars of tomato
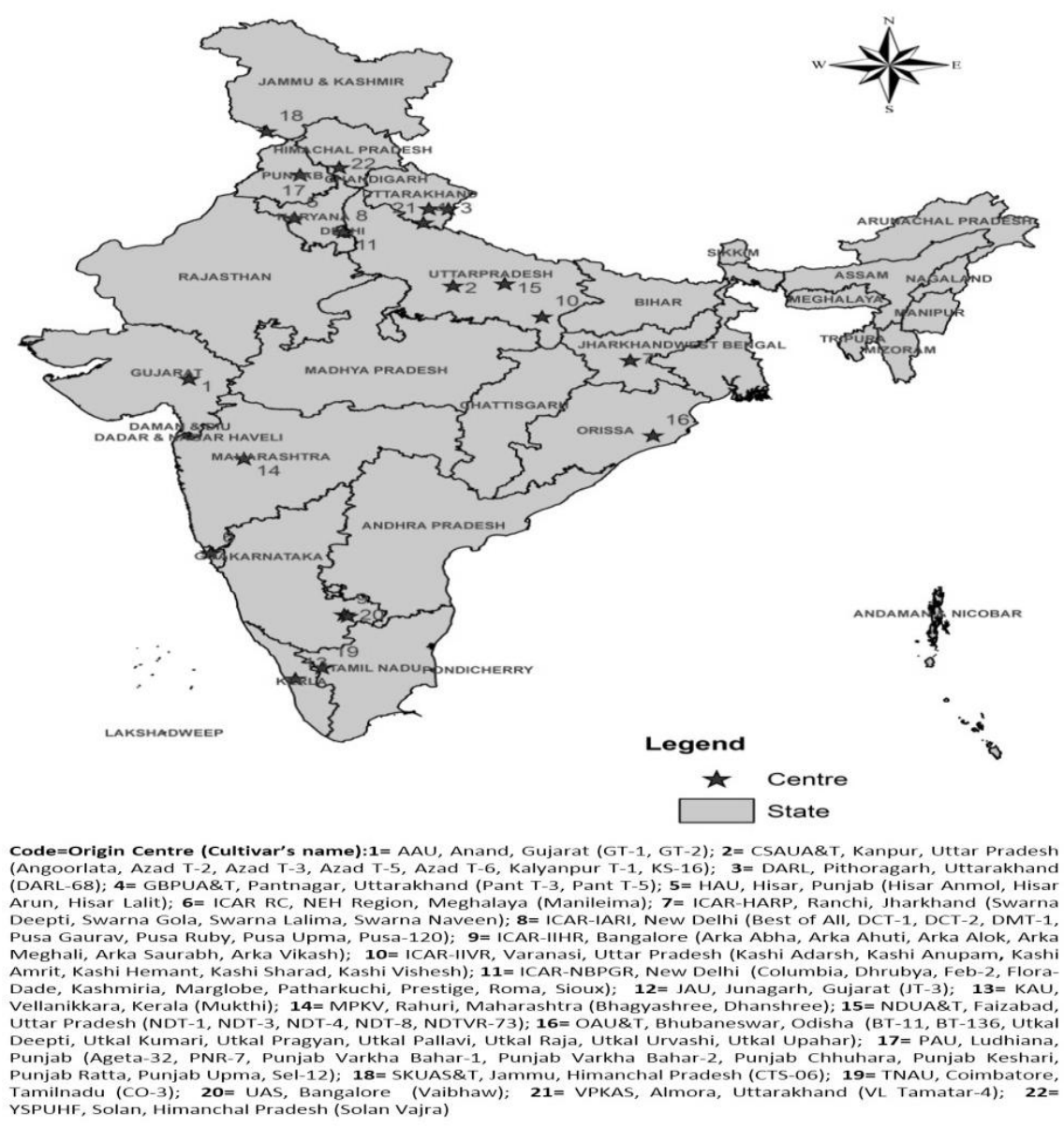

Fig.2 3D plot of principal component analysis (PCA) for 82 extant cultivars of tomato based on 20 characters

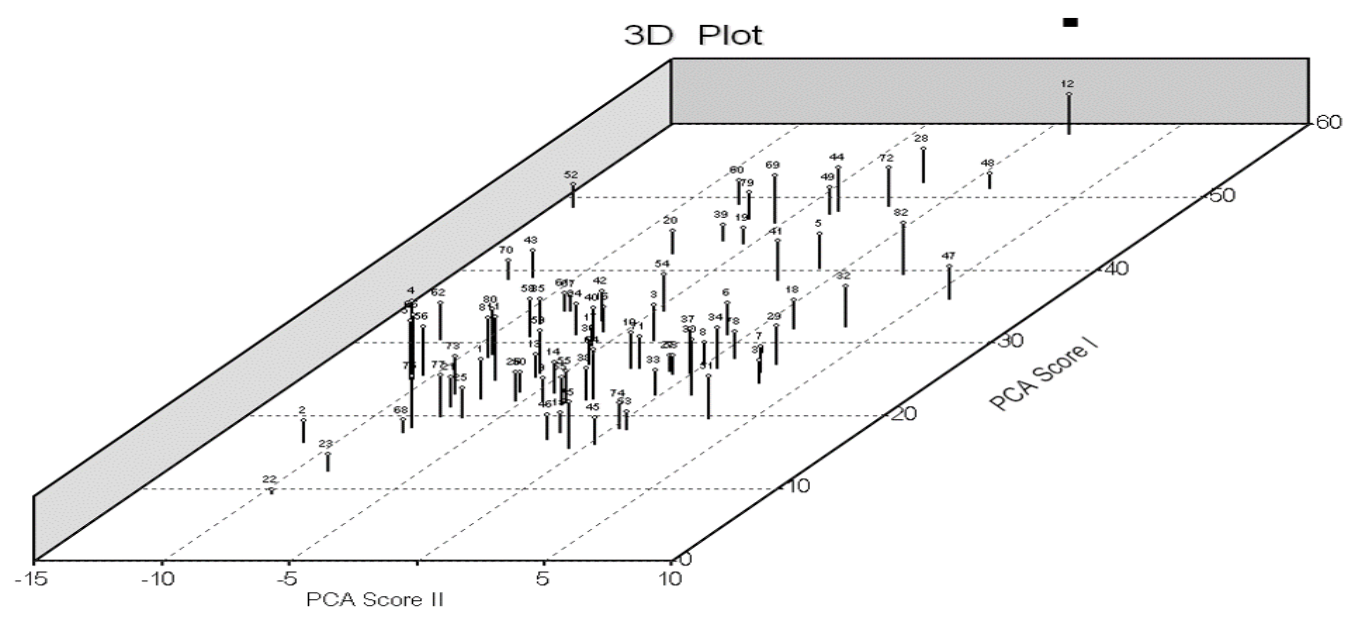


Fig. $3 \mathrm{D}^{2}$ Cluster dendrogram constructed by Tocher's method from 82 extant cultivars of tomato for 20 characteristics

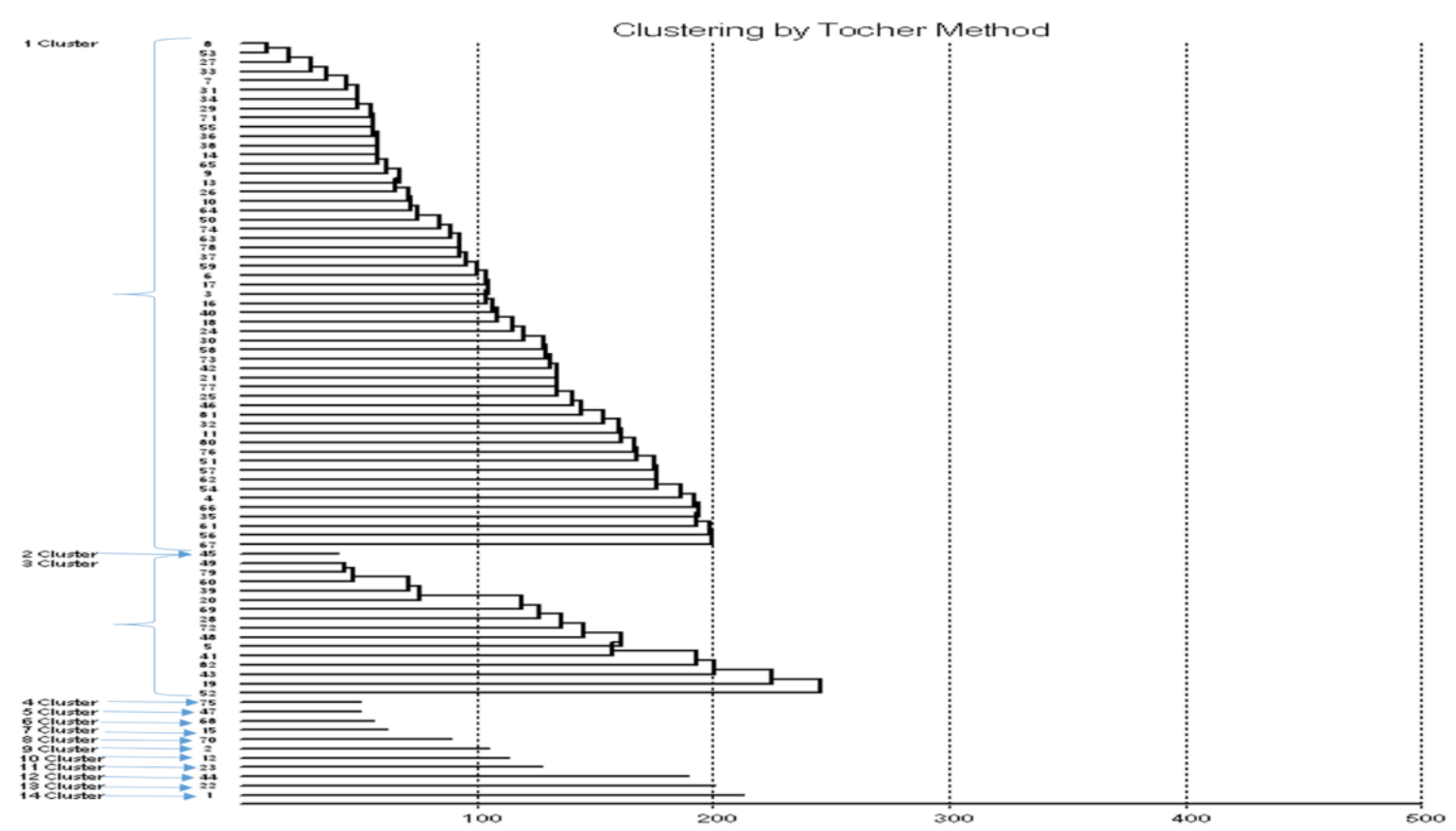

The most important characters of this group were total yield $(\mathrm{kg}) / \mathrm{plant}$, number of fruits/plant, $\mathrm{PDI} \%$ of EB and Stem length of internodes with highest PCA values-0.74791, $0.39747,0.38279$ and 0.24888 , respectively (Table 4). While, the lowest PCA IV value was 0.00478 for average fruit weight.

\section{Mahalanobis $\mathrm{D}^{2}$ cluster distances or multivariate analysis}

Based on the variation, 82 extant cultivars of tomato were grouped into fourteen clusters (Figure 3). Cluster ' 1 ' confined with the highest number of genotypes (55) followed by clusters ' 3 ' (15) and remaining clusters ' 2 ', '4', '5', '6', '7', '8', '9', '10', '11', '12', '13' and ' 14 ' had single genotype (Figure 3 ). The highest mean of relative stem length internodes and time of maturity was observed in cluster ' 11 ' and leaf length, leaf width and flower calyx size were highest in cluster ' 8 '. While, the character leaflet length was highest in cluster '14'. However, highest mean of relative characters leaflet width, joint peduncle length, fruit length, fruit width, size of scar around peduncle, size of core in cross section, thickness of the pericarp and PDI\% for ToLCV were highest in cluster ' 12 '. Whereas, most of characters like time of 50\% flowering, average fruit weight, number of fruits/plant, PDI\% for EB and total yield/plant went with the clusters ' 7 ', ' 10 ', ' '13', ' 4 ' and ' 9 ', respectively. In the present study relative number of locules was grouped with two clusters ' 5 ' and ' 10 '. It was also observed that most of characters showed their highest values in cluster ' 12 '. Whereas, a character time of maturity was confined with highest value in all clusters. Pair wise Mahalanobis distances $\left(\mathrm{D}^{2}\right.$ statistics) were offered fourteen clusters those were statistically different from each other (Table 5, Figure 3). Maximum intra cluster distance was elucidated in cluster '3' (13.79) followed by cluster ' 1 ' (11.93) but minimum intra cluster distance value was obtained zero in remaining clusters (Table 5). Whereas, maximum inter cluster distance 
(52.95) was recorded between cluster ' 11 ' and ' 13 ' and lowest (7.11) was observed between cluster ' 4 ' and ' 6 '. Cluster ' 10 ' had those genotypes performed well with most of the characters. In contrast, the genotypes grouped in cluster ' 14 ' performed very poorly.

In present study, all the extant cultivars were infected by ToLCV only three cultivars namely 'Punjab Varkha Bahar-1', 'Punjab Varkha Bahar-2' and 'Swarna Naveen' were showed moderately resistant reaction. No any cultivar was highly resistant or resistant. It may be due to these three cultivars contain vigorous growth or some special fragrance which causes they have less attack by whiteflies. Previously, it has been reported that the presence of indeterminate growth habit and special fragrances are indicated the resistance capacity in tomato crop (Singh et $a l ., 2015$; 2019). It has also been studied that abundantly resistance available in wild accessions but few in cultivated $(S$. lycopersicum) background and still to be introduced (Chaerani and Voorrips, 2006; Singh et al., 2010; 2015; 2019). Whereas, only 'Kashi Sharad' was highly resistant but remaining cultivars were susceptible against EB disease. Resistance reaction of 'Kashi Sharad' may be reason of its strong morphology and late flowering and fruiting. Because in previous study it has been discussed that the early maturing tomato cultivars with determinate growth habits were more susceptible to early blight, and disease also develops quickly during natural epidemics at the time of fruit set (Pandey et al., 2003; Chaerani and Voorrips, 2006). In support of this study Pandey et al., (2003) and Mate et al., (2005) has explained that tomato genotypes which were indeterminate in growth produce continuously new leaves and given late flowering and fruiting or late maturing exhibited high resistance to $\mathrm{EB}$ (Singh et al., 2017; Ramesh and Praveen, 2019).

Universally, resistance/moderately resistance sources has been identified for early blight disease in tomato cultivars (Mate et al., 2005; Chaerani and Voorrips, 2006; Singh et al., 2012; 2017).

A considerable variation was recorded for ECV, PCV and GCV in most of the characters. In finding of present study the maximum and minimum range of mean values were observed for average fruit weight and flower calyx size, respectively. While, the general mean value was highest and lowest for time of maturity and thickness of pericarp, respectively. High mean range reported for plant height, fruit weight, and flowering time in some previous studies (Singh et al., 2001; Ahmed et al., 2006; Shashikanth et al., 2010; Rani and Anitha, 2011; Spaldon and Kumar, 2017; Saravanan et al., 2019).

Whereas, the lowest and highest environmental variances were found of flower calyx size and time of maturity and PDI for ToLCV, respectively. It means environmental variances are influenced directly with the time of maturity and ToLCV disease incidence. This study is supported with agreement of other relevant studies (Mohamed et al., 2012; Singh et al., 2015). The lowest and highest genotypical and phenotypical variances reported for fruit cluster size and average fruit weight which may be directly influenced by the genotype $\mathrm{x}$ environmental interaction (Singh et al., 2001; Ahmed et al., 2006; Shashikanth et al., 2010; Mohamed et al., 2012).

Among the characters, most of the characters showed less difference between GCV and PCV values. The lesser difference between GCV and PCV for morphometric traits indicated additive gene action and strong genotypic interaction with less environmental effects (Ahmed et al., 2006, Shashikanth et al., 2010; Saravanan et al., 2019). The lowest and highest environmental coefficient of 
variation indicated to environmental influences over the characters (Shashikanth et al., 2010).

The lowest and highest values for genotypic and phenotypic coefficient of variation represented to outward dissimilarity due to genotypes and more inspiration of environment. Similar results reported by Singh et al., (2001); Ahmed et al., (2006); Rani and Anitha (2011). In present study it was revealed that two values varied in narrow variability, it may be due to the genetic makeup of genotypes and more inconsistency utilised by the environmental factor. Wide difference of ECV from GCV and PCV for PDI\% of early blight indicated direct relation of susceptibility by environmental fluctuation and the selection of desirable traits for highly variable characters would be effective in tomato improvement programme (Singh et al., 2001; Shashikanth et al., 2010; Rani and Anitha, 2011; Singh et al., 2017).

The genotypic coefficient of variation along with heritability estimates provide best scope for phenotypic selection and gives the reliable estimate of the amount of genetic advance (Burton and deDevane, 1953; Singh et al., 2001; Ahmed et al., 2006).

The highest heritability with high genetic advance for traits exhibited additive gene action and are very useful to plant breeder for making effective selection during breeding programs (Singh et al., 2001; Ahmed et al., 2006; Shashikanth et al., 2010; Mohamed et al., 2012; Reddy et al., 2013; Spaldon and Kumar, 2017). However, the lowest heritability and genetic advance are revealed non-additive (dominant or epistatic) gene action which barriers for tomato improvement through selection (Ahmed et al., 2006; Mohamed et al., 2012; Reddy et al., 2013; Saravanan et al., 2019).
Principal component analysis (PCA) helps in extracting important variables from huge variables available in a data set and it is more useful when arrangement with higher dimensional data. In present study, the principal component analysis was showed the three-dimensional principal component score plot for most variation. This fact is allowed to identify those sensory attributes which are more influenced by environmental conditions and genetic constitution of tomato cultivars. Similar studies were reported by Iqbal et al., (2014); Nankar et al., (2020).

In the first principal component (PCA I), the most important traits were average fruit weight, number of fruit per plant, number of locules and size of scar around fruit peduncle but the minimum and maximum value was found for leaflet width and average fruit weight, respectively. Variation in average fruit weight and leaflet width are depending on the environmental fluctuation, time of transplanting, and varying as per tomato varieties and fixed with genetically.

The fruit numbers in tomato plants may reduce due to largest fruit size but may increase when size of fruits are smallest or medium. This finding is an agreement with a previous study of Glogovac et al., (2012). In the second principal component (PCA II), the most important characters with high value of this component defined by number of locules, total yield per plant, fruit length, leaflet length, thickness of the pericarp and fruit width. These characters are depending on nature of genetics of tomato cultivars as well as varying due to environmental factors (Gonzalo and Knaap, 2008; Hair et al., 2009; Glogovac et al., 2012; Iqbal et al., 2014; Nankar et al., 2020). Whereas, in the third principal component (PCA III) the most important traits were $\mathrm{PDI} \%$ for $\mathrm{EB}$, fruit length, total yield per plant and time of 50\% flowering. 
The fruit length and time flowering are influencing fixed genetic characters and slightly depend on environment but the fruit yield and early blight are more affected by environmental instability. This finding is supported by some studies were published on morphological traits and early blight disease (Gonzalo and Knaap, 2008; Singh et al., 2012; 2017; Nankar et al., 2020). While, in fourth component (PCA IV) the most important characters of this group were total yield $(\mathrm{kg}) /$ plant, number of fruits/plant, PDI\% of $\mathrm{EB}$ and Stem length of internodes with highest PCA.

Total yield per plant is depend upon plant growth habit, number of node and internodes, number of flowers, number of fruits, average fruit weight and genetic architecture of plants. Yield is most required character from any crop for fulfilling the need of livelihood as has been discussed in many studies (Gonzalo and Knaap, 2008; Iqbal et al., 2014; Kumar et al., 2017; Nankar et al., 2020).

During $D^{2}$ cluster analysis all the 82 extant cultivars of tomato were grouped into fourteen clusters. It was also found that the cluster ' 1 ' and clusters ' 3 ' had highest number of genotypes and remaining clusters had single genotype. Those genotypes were single in a group indicated diverse characteristics from each other. This finding is in agreement with Iqbal et al., (2014); Spaldon and Kumar (2017). The highest mean of relatives of the characters were found in various clusters. These results are in accordance with the findings of Evgenidis $e t$ al., (2011); Iqbal et al., (2014); Spaldon and Kumar (2017); Kumar et al., (2017) in tomato. Pair wise Mahalanobis distances $\left(\mathrm{D}^{2}\right.$ statistics) were offered fourteen clusters but some cluster had the minimum (zero) intra cluster distance value, and maximum inter cluster distance was recorded in cluster ' 11 ' and ' 13 ', while, cluster ' 14 ' performed very poor which may be indicated least value of genetic divergence in tomato (Evgenidis et al., 2011; Iqbal et al., 2014; Kumar et al., 2017; Spaldon and Kumar, 2017; Nankar et al., 2020). This is an evident from current study that the cluster analysis can be recorded as efficient tools to categorize germplasm as base material to plan future breeding strategies in tomato (Iqbal et al., 2014; Kumar et al., 2017; Spaldon and Kumar, 2017; Nankar et al., 2020).

From the study, it was concluded that the cultivars 'Punjab Varkha Bahar-1', 'Punjab Varkha Bahar-2', 'Swarna Naveen' and 'Kashi Sharad' were exhibited resistant to ToLCV and EB diseases and can be utilized in resistant breeding programme. The extant cultivars of tomato exhibited a wide range of variability and heritability for morpho-metric traits.

The highest and lowest heritability with genetic advance for the important traits exhibited both additive and non-additive gene action which plays a major role in governing these traits and these traits can be improved by simple selection. Principal component analysis (PCA) workout with limited and important variables available in a data set and very useful to plant breeder for making effective breeding programs. However, multivariate analysis could effectively be used in identifying the tomato extant cultivars with desirable traits for improving resistant and high yield capacity. On behalf of the distinct characteristics these extant cultivars of tomato may be protected under PPV\&FRA, New Delhi.

\section{Acknowledgement}

Authors gratefully thanks to financial support of PPV\&FRA, New Delhi and staff engaged under DUS project entitled "Central Sector Scheme for Protection of Plant Cultivars and 
Farmers Rights Authority (DUS Testing in Vegetable Crops)" at ICAR-IIVR, Varanasi.

\section{References}

Ahmed, N., M.I. Khan and Gupta A.J. 2006. Variability and heritability in tomato (Lycopersicon esculentum Mill.). Environ and Eco. 24(2): 386-388.

Burton, G.W. and deDevane, E.H. 1953. Estimating heritability in tall fescue (Festuca arundinacea) from replicated clonal material. Agron J. 45: 478 - 481.

Chaerani, R. and Voorrips, R.E. 2006. Tomato early blight (Alternaria solani): the pathogen, genetics, and breeding for resistance. J Genet Plant Pathol. 72: 335347.

Evgenidis, G., E. Traka-Mavrona and Koutsika-Sotiriou, M. 2011. Principal component and clusters analysis as a tool in the assessment of tomato hybrids and cultivars. Int J Agr. Volume 2011, 7 pages;

http://dx.doi.org/10.1155/2011/697879.

Foolad, M.R. 2007. Genome mapping and molecular breeding of tomato. Int J Plant Genom. (Published online 28 Aug, 2007; DOI: $10.1155 / 2007 / 64358)$.

Glogovac, S., A. Takac, A. Tepic, Z. Sumic, J. Gvozdanovic-Varga, J. Cervenski, M. Vasic and Popovic, V. 2012. Principal Component Analysis of Tomato Genotypes Based on Some Morphological and Biochemical Quality Indicators. Ratarstvo and povrtarstvo. 49(3): 296301.

Gonzalo, M.J. and Knaap, E.V. 2008. A comparative analysis into the genetic bases of morphology in tomato varieties exhibiting elongated fruit shape. Theor Appl Genet. 116: 647-656.

Hair, J.F., R.E. Anderson, R.L. Tatham, and Black, W.C. 2009. Multivariate Data Analysis. 6ed. Prentice Hall, New York, NY, USA. Hanson, C.H., H.F. Robinson and Comstock, R.E. 1956. Biometrical studies of yield in segregating population of Korean lespedeza. Agron J. 47: 268-272.

Iqbal, Q., Y.S. Muhammad, A. Hameed and Muhammad, A. 2014. Assessment of genetic divergence in tomato through agglomerative hierarchical clustering and principal component analysis. Pak J Botany. 46(5): 1865-1870.

Johnson, H.W., H.F. Robinson, Comstock, R.E. 1955. Estimates of genetic and environmental variability in soybeans. Agron J. 47:314-318.

Kissoudis, C., C. van de Wiel, R.G.F. Visser and Van Der Linden G. 2014. Enhancing crop resilience to combined abiotic and biotic stress through the dissection of physiological and molecular crosstalk. Front Plant Sci. 5: 207.

Kumar, N., M.L. Bhardwaj, A. Sharma, and Kumar, N. 2017. Assessment of genetic divergence in tomato (Solanum lycopersicum L.) through clustering and principal component analysis under Mid Hills Conditions of Himachal Pradesh, India. Int $\mathbf{J}$ Curr Microbiol Applied Sci. 6(5): 1811-1819.

Mahalanobis, P.C. 1936. On the generalized distance in statistics. Proceed Nat Acad Sci (India). 2: 49-55.

Mate, G.D., V.V. Deshmukh, D.J. Jiotode, N.S. Chore, Mayur, D. 2005. Screening of tomato cultivars for resistant to early blight. Res Crops. 6(2): 352-357.

Mohamed, S.M., E.E. Ali and Mohamed, T.Y. 2012. Study of heritability and genetic variability among different plant and fruit characters of tomato (Solanum lycopersicon L.). Int J Sci Tech Res. 1(2): 55-58.

Nankar, A.N., I. Tringovska, S. Grozeva, D. Ganeva and Kostova, D. 2020. Tomato Phenotypic Diversity Determined by Combined Approaches of Conventional and High-Throughput Tomato Analyzer Phenotyping. Plants. 9: 197-218.

Pandey, K.K., P.K. Pandey, G. Kalloo and Banerjee, M.K. 2003. Resistance to early blight of tomato with respect to various parameters of disease epidemics. J Gen 
Plant Pathol. 69: 364-371.

PPV\&FRA. 2009. Test guidelines applied for all varieties, hybrids and parental lines of tomato (Solanum lycopersicum L.). Plant Var J. 03(11).

Ramesh, K.T. and Praveen, K.M. 2019. Survey and Screening of Tomato Varieties against Early Blight (Alternaria solani) Under Field Condition. Int J Pure App Biosci. 7(2): 629-635.

Rani, R. and Anitha, V. 2011. Studies on variability, heritability and genetic advance in tomato (Lycopersicon esculentum M.). Int J Biores Stress Manag. 2(4): 382-385.

Reddy, B.R., D.S. Reddy, K. Reddaiah and Sunil, N. 2013. Studies on genetic variability, heritability and genetic advance for yield and quality traits in Tomato (Solanum lycopersicum L). Int J Curr Microb App Sci. 2(9): 238-244.

Saravanan, K.R., V. Vishnupriya, M. Prakash and Anandan, R. 2019. Variability, heritability and genetic advance in tomato genotypes. Ind J Agric Res. 53:92-95.

Shashikanth, N., R.M. Basavaraj, B. Hosamani and Patil, C. 2010. Genetic variability in tomato (Solanum lycopersicon [Mill]. Wettsd.). Karn J Agr Sci. 23(3): 536-537.

Singh, A.K., N. Rai, R.K. Singh, S. Saha, R.K. Rai and Singh, R.P. 2017. Genetics of resistance to early blight disease in crosses of wild derivatives of tomato. Sci Hort. 219: 70-78.

Singh, A.K., N. Rai, R.K. Singh, M. Singh, R.P. Singh, S. Singh and Singh, S. 2012.
Selection of resistant source to early blight disease in tomato among the Solanum spp. J App Hort. 14(1): 40-46.

Singh, B., S.P. Singh, D. Kumar and Verma, H.P.S. 2001. Studies on variability, heritability and genetic advance in tomato. Prog Agr. 1(2): 76-78.

Singh, R.K. and Chaudhary, B.D. 1985. Biometrical methods of quantitative genetic analysis. Har J Hort Sci. 12(2): 151-156.

Singh, R.K., N. Rai and Singh, S.N. 2010. Response of tomato genotypes to tomato leaf curl virus. Ind J Agr Sci. 80(8): 755758.

Singh, R.K., N. Rai, M. Singh, S. Saha and Singh, S.N. 2015. Detection of tomato leaf curl virus resistance and inheritance in tomato (Solanum lycopersicum L.). J Agr Sci, Cambridge. 153(1): 78-89.

Singh, R.K., N. Rai, M. Singh, S.N. Singh and Srivastava, K. 2014. Genetic analysis to identify good combiners for ToLCV resistance and yield components in tomato using inter-specific hybridization. $\mathbf{J}$ Genet. 93(3): 623-629.

Singh, R.K., N. Rai, A.K. Singh, P. Kumar and Singh, B. 2019. A critical review on Tomato Leaf Curl Virus resistance in Tomato. Int J Veg Sci. 25(4): 373-393.

Spaldon, S. and Kumar, S. 2017. Genetic divergence studies for quantative and quality traits in tomato (Solanum lycopersicum L.). Int J Agr Env Biotech. 2(3): 1227-1231.

\section{How to cite this article:}

Bijendra Singh, Tribhuvan Chaubey, Sudhakar Pandey, Ramesh Kumar Singh and Dhananjay Kumar Upadhyay. 2020. Heritable Variability and Multivariate Analysis for Physio-MorphoMetric Traits in Tomato (Solanum lycopersicum L.). Int.J.Curr.Microbiol.App.Sci. 9(11): 34523466. doi: https://doi.org/10.20546/ijcmas.2020.911.412 